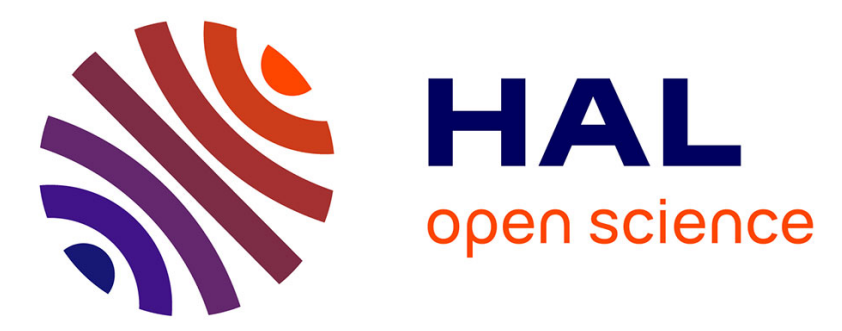

\title{
La experiencia estética popular: elementos para la acción descolonial. \\ Inés Pérez-Wilke
}

\section{To cite this version:}

Inés Pérez-Wilke. La experiencia estética popular: elementos para la acción descolonial.. Communiars. Revista de Imagen, Artes y Educación Crítica y Social, 2020, pp.98 - 115. 10.12795/Communiars . hal-03217352

\section{HAL Id: hal-03217352 \\ https://hal.science/hal-03217352}

Submitted on 4 May 2021

HAL is a multi-disciplinary open access archive for the deposit and dissemination of scientific research documents, whether they are published or not. The documents may come from teaching and research institutions in France or abroad, or from public or private research centers.
L'archive ouverte pluridisciplinaire HAL, est destinée au dépôt et à la diffusion de documents scientifiques de niveau recherche, publiés ou non, émanant des établissements d'enseignement et de recherche français ou étrangers, des laboratoires publics ou privés.

\section{(1) (1) $\$$}

Distributed under a Creative Commons Attribution - NonCommercial - NoDerivatives| 4.0 


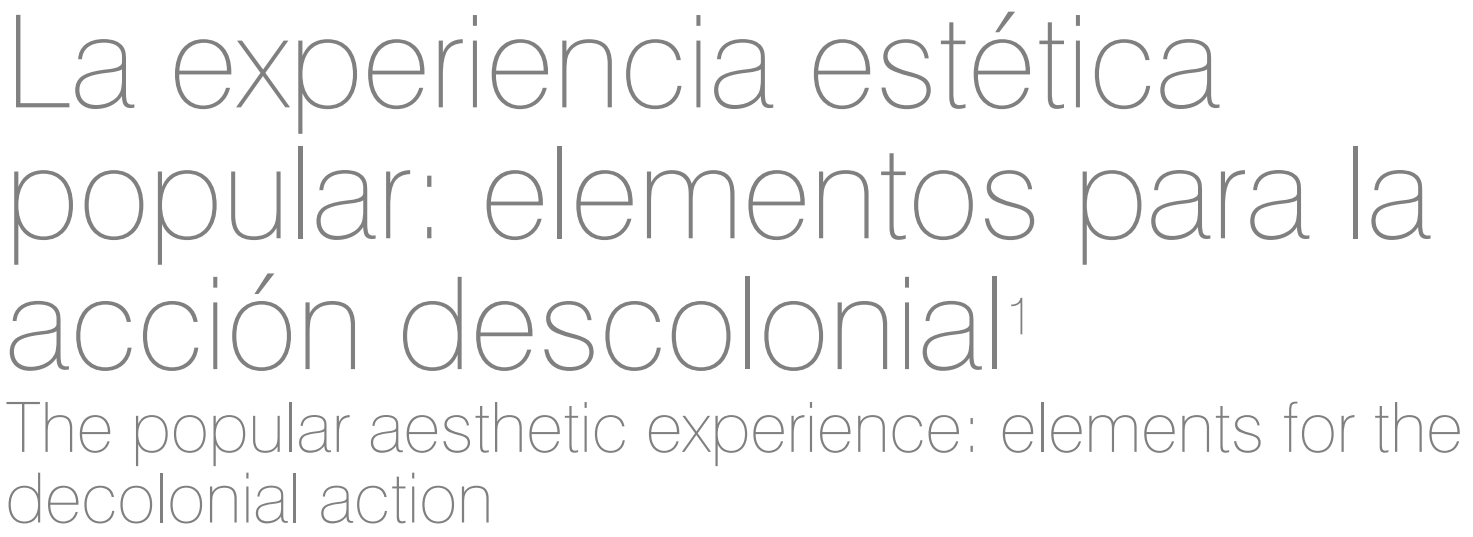

INÉS PÉREZ WILKE | inesperez@unearte.edu.ve
UNIVERSIDAD NACIONAL EXPERIMENTAL DE LAS ARTES. UNEARTE | VENEZUELA

Recibido: 30 de octubre de 2018 | Aceptado: 21 de enero de 2019

DOI: https://dx.doi.org/10.12795/Communiars.2019.i02.07

(c) (1) (2)(-) Artículo bajo licencia Creative Commons BY-NC-SA

Cómo citar este artículo:

Pérez-Wilke, I. (2019). La experiencia estética popular: elementos para la acción descolonial. Communiars. Revista de Imagen, Artes y Educacion Crítica y Social,2, 98-115.

\section{Resumen:}

Se presentan claves emergentes de la producción popular en el campo cultural que prefiguran elementos para pensar una estética descolonial. Esto implica identificar, a partir de experiencias, acciones y perspectivas estéticas de base, eludidas por las corrientes hegemónicas de valoración del arte, elementos claves para la comprensión de la experiencia estética popular, mostrando vectores de mucha potencia para rehabitar la producción y la experiencia sensible en la vida contemporánea, en sentido amplio e incluyente. En primer lugar la idea de materia afectable transformativa como condición de la vida e instancia en la que opera la acción estética; en segundo lugar la idea de creación artística re-encarnada en la cotidianidad y en las actividades de cuidado de la vida; en tercer lugar la comprensión del hecho estético como tecnología de transformación de la realidad social; en cuarto lugar, la agencia colectiva como noción operadora de la experiencia de lo común; en quinto lugar se muestra la potencia política de contra-interferencia, a través de la experiencia estética. Estos elementos en su conjunto configuran condiciones para la emergencia de experiencias estéticas situadas, operativas, decoloniales y transformativas.

\section{Palabras Claves:}

Arte popular; arte y política; experiencia estética; pensamiento descolonial.

\footnotetext{
${ }^{1}$ Estas ideas fueron presentadas en el Seminario “Mediaciones Estéticas Descoloniales", que coordiné entre los meses de marzo y junio en la Universidad Experimental de las Artes de Venezuela en el marco del Programa de Formación Avanzada en Artes y Culturas del Sur. Se presenta aquí una versión revisada y sintética de estas ideas e intervenciones que se sucedieron en diversos momentos durante el seminario, y que vienen dialogando con trabajos anteriores como “Otras narrativas" (2017) y “La Experiencia de 1@s Otr@s" (2016).
} 


\section{Abstract:}

Emerging keys of popular production are presented in the cultural field that prefigure elements to think a decolonial aesthetic. This implies identifying, from experiences, aesthetic actions and perspectives, eluded by the hegemonic currents of art valuation, important elements for the understanding of the popular aesthetic experience and shows how these are vectors of great power to rehabite production and experience sensitive in contemporaneous life, in a broad and inclusive sense. We have in the first place, the idea of affectable matter as a condition of life and the instance in which the aesthetic action operates; second, the idea of artistic creation re-incarnated in everyday life and its activities of care for life; third, the understanding of the aesthetic fact as a technology for the transformation of social reality; Fourth, the collective agency as a notion that operates the experience of the common; Fifth, is show how the aesthetic experience is a political power of possible counterinterference. These elements as a whole configure conditions for the emergence of situated, operative, decolonial and transformatives aesthetic experiences.

Key Words:

Aesthetic experience; arts and politic; decolonial thinking; popular art.

\section{Introducción}

Presentamos las ideas centrales en torno a la experiencia estética, desarrolladas junto a grupos culturales comunitarios y en diálogo con autores que vienen señalando el campo de la sensibilidad como central en las dinámicas sociales, en tanto aportes para el debate sobre la mediación estética como fuerza de operación transformadora para la experiencia vital, sensible, descolonial de la vida contemporánea. La agencia estética es pensada como elemento clave en la mediación de procesos de sinergia social para la producción y materialización de contenidos que emergen en el campo simbólico, expresados en la movilización de las subjetividades y las prácticas sociales. En este escenario vemos la persistencia de formas populares de producción cultural, que pueden estar asociadas a acervos tradicionales o a la emergencia de formas de enunciación urbana, que materializan necesidades y campos simbólicos locales y cuyas claves creadoras pueden aportar a las dinámicas contemporáneas de rehabitación de las fuerzas colectivas de producción cultural. Esta propuesta viene a sumar a la labor de construcción teórica para pensar una estética descolonial o transmoderna, al decir de Bautista Segales'; a la que ya vienen contribuyendo autores como Walter Mignolo (2012), Adolfo Alban (2013) o Suely Rolnik(2007) desde distintas perspectivas.

Han existido, en tensión y en paralelo a la sociedad legitimada por los procesos coloniales, y las formas actuales de sujeción que perviven como colonialidad (Grosfoguel, 2007), experiencias de los pueblos con proyectos y agencias descoloniales en muchas formas del hacer estético (Figura 1). El campo cultural, así como ha sido un blanco del ejercicio del poder autoritario a través del lenguaje, la religión, del establecimiento de jerarquías étnicas, potenciadas en formas de biocontrol social y perfeccionadas a través de la industria

\footnotetext{
${ }^{2}$ Entrevista al Prof. Juan José Bautista Por el Grupo Caracara, en el marco de la 1era Escuela de Pensamiento crítico Descolonial. UNEARTE, 2018. Recuperado de https://www.youtube.com/watch?v=cVhO_Kg2Xc4
} 
comunicacional, también ha sido un campo potente de resistencias, recreaciones, subversiones por parte de los pueblos marginalizados, folklorizados, minorizados y/o valorados negativamente como acervos epistémicos. Sin embargo, existen dificultades en hacer presentes plenamente estas experiencias, como contribución a dinámicas sociales más democráticas, incluyentes, respetuosas de la diversidad y de la creatividad social comunitaria. Estas limitaciones están vinculadas al reduccionismo conceptual que caracteriza los aparatos hegemónicos de validación del arte, el conocimiento y la cultura en general. Esto hace que estas experiencias negadas pero existentes no encuentren soportes más allá de la memoria popular, debiendo disputar con mucha beligerancia espacios de legitimidad.

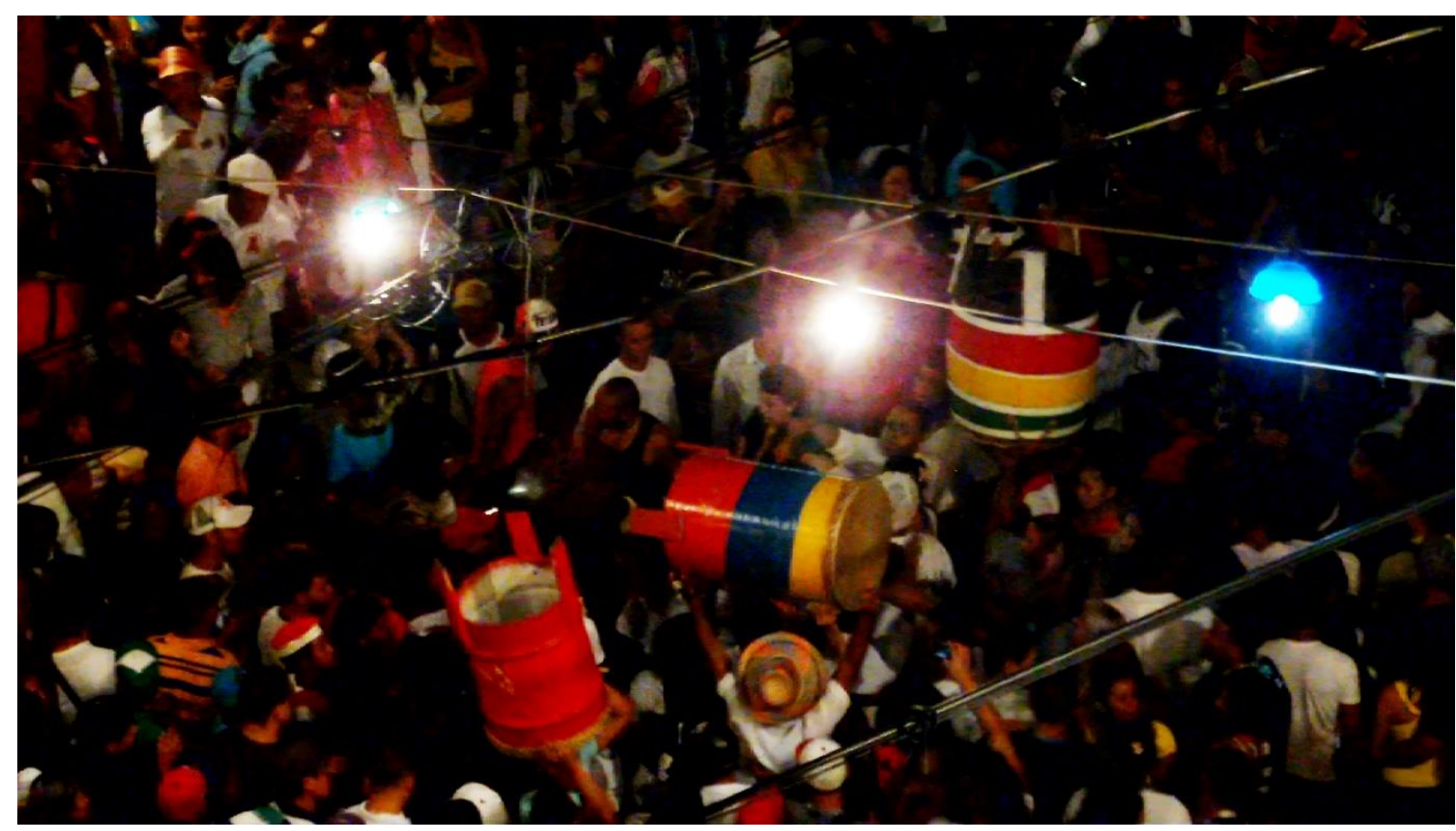

Figura 1. Fiesta de San Juan de la Vega, Caracas, Venezuela, 2012. Fotografía Nelson Rojas.

Para los pueblos del sur nacidos y formados bajo una fuerte marca colonial, pueblos en resistencia que han guardado la continuidad de muchos de sus saberes, se trata al tiempo de responder a las fuerzas de la sociedad legitimada, de hacer ver su participación de la dinámica contemporánea; y al mismo tiempo de dar continuidad a formas de comprensión de la vida y del mundo que como archivo común de saber es patrimonio de su pueblo. Esto implica el desarrollo y la visibilización de formas de registro y de racionalidad locales en ámbitos de debate globales, como formas colectivas de pensamiento.

Se efectúa aquí un desplazamiento del lugar de comprensión y de enunciación, para asumir territorios marginados como punto de perspectiva, desde donde el mundo se observa sin ser visto, sin que esa mirada sea incorporada a la narrativa social, y desde allí hacer emerger las claves de estas formas de agencia cultural. La experiencia de creación cultural popular muestra elementos que pueden esclarecer nudos críticos en los debates sobre la producción y control de la subjetividad en la actualidad; lugar donde se perciben y experimentan los dobleces, contradicciones de lo social. En ese contexto la experiencia estética popular se remite a una honestidad cruda, que no disimula sus dolores, y que utiliza tipos de racionalidad impregandos del saber y la tradición local, vistos en occidente como supersticiones, costumbres, saberes minorizados y desacreditados pero que perviven en el uso popular y 
representan formas de regulación de las operaciones subjetivas que transitan los pueblos subalternizados. Esta perspectiva, irreconocible desde el marco de discursos dominantes, coloca retos a la experiencia estética que las formas artísticas de salón no podrían ver y por ello incorporar plenamente. Estas funciones de mediación estética serían parte de un aparato productor de imaginarios, subjetividades, así como de sus formas de expresión material, de las cuales el propio sujeto es su producción privilegiada.

En este sentido nos proponemos puntualizar cinco elementos desarrollados a partir del encuentro con experiencias, históricas y contemporáneas, de producción cultural popular, que posibilitan vislumbrar un camino para pensar, potenciar, cuidar, agenciar, producir territorios y experiencias estéticas populares, descoloniales, liberadoras, transmodernas. Este párrafo resulta bastante confuso por la disposición de los signos de puntuación. De este modo tenemos, en primer lugar, la idea de materia afectable transformativa como condición de la vida e instancia en la que opera la acción estética en condiciones de vulnerabilidad; en segundo lugar, la idea de creación artística re-encarnada en la cotidianidad y en las actividades de cuidado de la vida que incorporan una dimensión poética; en tercer lugar, la comprensión del hecho estético como tecnología de transformación de la realidad social con consecuencias registradas; en cuarto lugar, la agencia colectiva como noción operadora de lo común, indispensable a la agencia estética; en quinto lugar, se muestra la potencia política de contra-interferencia, a través de la producción en el campo de la sensibilidad. Estos elementos en su conjunto configuran condiciones para la emergencia de experiencias estéticas situadas, operativas, decoloniales y transformativas.

Queremos llamar la atención, antes de comenzar, sobre nuestra afinidad con el giro descolonial como parte formalizada y académica de un pensamiento autonómico, que ha existido en todos los tiempos en los pueblos de Sur, entendido no solo geográficamente, sino como campo político de los pueblos colonizados, marginados o de cualquier forma empujados a lugares no visibles de la geopolítica regional o mundial. Nos proponemos aportar al debate descolonial en el campo de la estética a partir del diálogo con experiencias de diversos orígenes y tiempos que pensamos aportan elementos claves para la comprensión de las tensiones coloniales en la experiencias sensible y las vías de materialización de otros sentidos del campo estético.

\section{Vulnerabilidad y materia afectable}

Una teoría sobre la experiencia estética popular no consistiría, como se postuló en la modernidad europea para la filosofía estética, en desarrollos teóricos sobre la belleza y el arte, ni sobre esa forma de aprehensión directa de lo verdadero, parafraseando a Schopenhauer (2003). En el análisis que venimos haciendo concluimos que versaría sobre las fuerzas y formas que con-mocionan al ser humano. Se trata del poder productivo y transformativo que implica la condición sensible de la vida como materia de afectabilidad, pero también como agencia creadora.

En principio nos referiremos al ser humano, pero sin duda otras fuerzas vivas entran en juego en esa experiencia; no solo en aquella relación contemplativa de la naturaleza que fue asociada en Kant con lo sublime como más alto paradigma de la belleza, ella objetualizada frente al 
genio; si no en otro tipo de relaciones y tejidos de interdependencia con lo vivo, e incluso con la consideración de fuerzas espirituales como las ancestralidades para muchas comunidades, $\mathrm{u}$ otras formas de lo sagrado, que en estos contextos siguen participando de la producción de la vida.

Por con-mocionar entendemos, a partir de sus componentes: mover o alterar junto, o llevar a movimiento, lo cual implica una dimensión estética no referida a las formas o las obras en sí, sino al proceso de ser movido, tocado, afectado, trasladado de un punto a otro por una fuerza. Si pensamos lo humano como cuerpo material y simbólico vivo, cambiante, poroso, plástico, producido permanentemente como subjetividad encarnada, vemos un desplazamiento, absorción, metamorfosis, de mayor o menor intensidad, en eso que llamamos materia afectable de la vida. Este tejido de lo vivo no es pasivo, acciona a partir de la huella, de la fuerza del otro en sí y del desplazamiento producido; participa de ese desplazamiento o de esa transformación con mayor o menor poder de control y de afectación en relación a los contextos. Esto implica que ese cuerpo sensible material y simbólico está no solo en condiciones de ser afectado, si no de afectar, tiene capacidad transformativa y de agencia.

En ese mismo camino, la estética puede entenderse como una teoría sobre la vulnerabilidad. Aunque en la tradición latina esta palabra tiene una connotación negativa, versando sobre aquel o aquello que puede ser herido o dañado; afirmamos que esta posibilidad de ser herido, es condición para ser tocado, movido, transformado. Esta vulnerabilidad que nos pone al alcance de los otros, es una forma de lo que otros teóricos como Dussel (1984) Boal (2005), Albán (2013), han asociado al pueblo pobre, y está en vinculación con las historias de opresión. En los contextos marcados por la colonialidad y la desigualdad, la vulnerabilidad tiene peso como tragedia, como condición hetero-impuesta y hetero-construida que condena a amplios sectores sociales a una vida expuesta sin las condiciones mínimas de realización.

Nos proponemos pensarla como la voluntad común de renuncia a asumirse como sujeto reificado de poder, que implica ser vulnerable y estar con los vulnerables, asumiendo su lugar junto a los(as) otros(as), que se suman, se mantienen y se cultivan en vulnerabilidad. Esta sería al mismo tiempo que capacidad de ser tocado, y también potencia de tocar y producir territorio y vida, a pesar de los sistemas hostiles que se usan de la vulnerabilidad como herida a capturar y no como condición de apertura de lo vivo creador. Sería asumirse en su afectabilidadtransformatividad como uno más en la comunidad (Figura 2). Tal como propone Albán (2013), los pueblos han encoontrado en la creación un espacio para disputar la visibilidad de su universo simbólico emergente:

Quizá podamos pensar que en la diversidad de pensamientos, opciones de vida, maneras diferentes de hacer, sentir, actuar y pensar del mundo contemporáneo, el arte se esté constituyendo en las comunidades sujetos étnicos en un acto decolonial que interpela, increpa y pone en cuestión las narrativas de exclusión y marginalización. (pp. 451-452)

Pensamos un acercamiento a la realidad como tejido vivo y afectable, en un movimiento de apertura, procesamiento y producción a través de la operación estética. Estaría implícita la continuidad material-simbólica, por medio de la cual se hacen transitar contenidos materiales al campo simbólico; y en sentido inverso permiten la materialidad de determinadas producciones simbólicas, indispensable en la producción de la realidad social. Esto convierte la experiencia estética en un proceso co-determinante y co-determinado, fundado en la vulnerabilidad frente a la presencia de lo otro, de la otra y de los otros. 


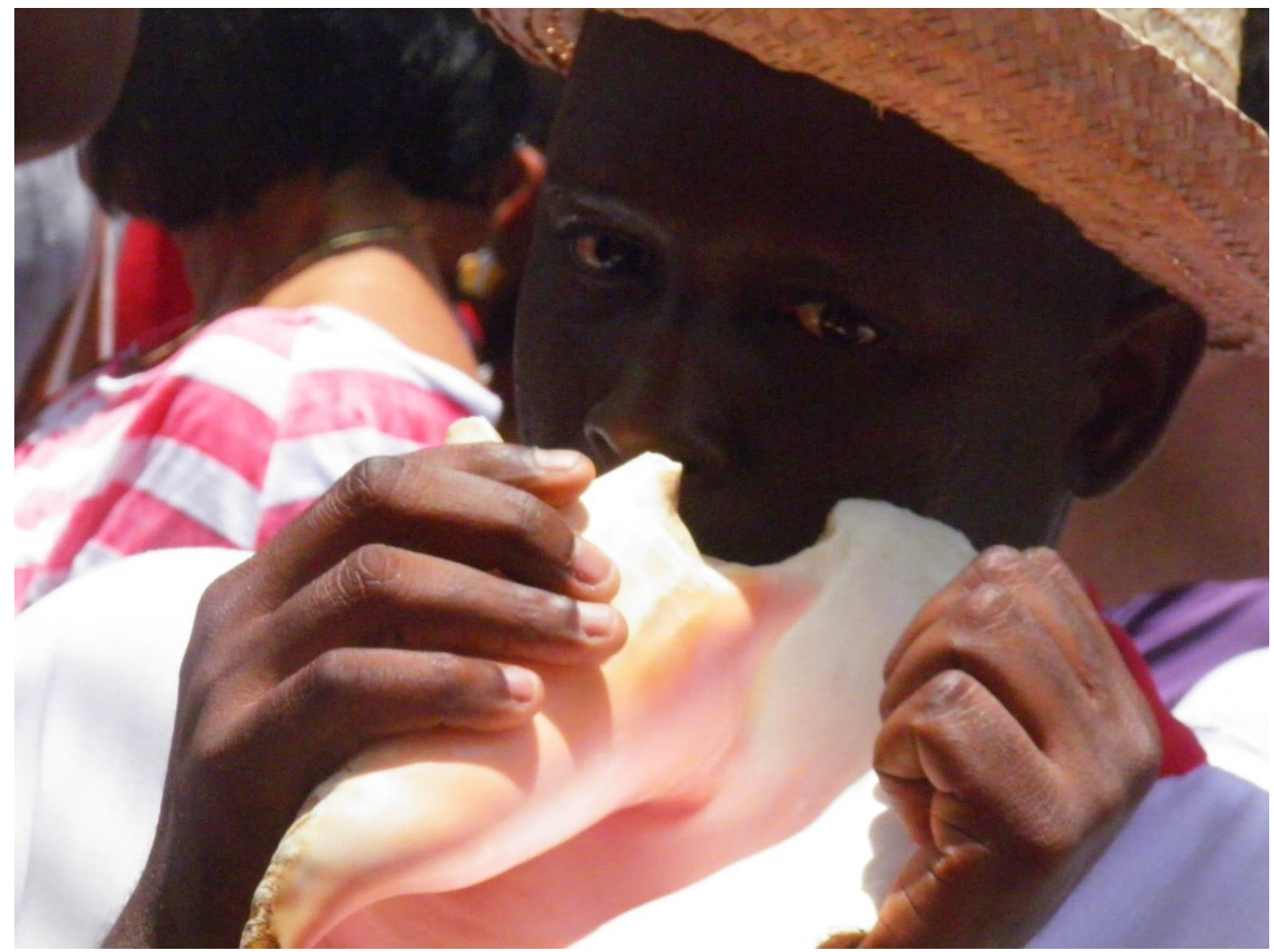

Figura 2. Tocador de guarura - Repique de San Juan de Curiepe-Venezuela, 2011. Fotografía Inés PérezWilke.

Esta corporalidad sensible de la vida la vemos expresada en el cuerpo vibratil de Rolnik (2007), caracterizándolo como aquella instancia en la cual la subjetividad es producida. Esta instancia clínico-estética, como la define la misma autora, la entendemos como cualidad sensible de la materia que se deja afectar, atravesar, transformar por las fuerzas que la tocan y más tarde lo expresa, lo enuncia clínicamente. Aquí el adjetivo clínico no remite al estudio de lo patológico, sino de los movimientos observables, registrables de la sensibilidad cuando se manifiesta.

El cuerpo es, sin duda, donde se constata con mayor intensidad la afectabilidad de la materia viva. Los cuerpos mortales, sensibles, atravesados por las experiencias de placer y dolor, modelados en sus forma de aparecer, encarnan la vulnerabilidad. Encontramos un amplio abanico de formas tradicionales populares para el tratamiento, configuración, escritura y performance corporal que pasa por formas de movimiento, de vestuario, de pintura, de marcaje del cuerpo. La propia construcción identitaria y comunitaria pasa por esta producción de corporalidades singulares en diálogo con los contextos. Una vez más, la diferencia y la disputa se da en relación a las marcas exógenas que sujetan el cuerpo por vía de las determinaciones sociales impuestas, a través de dispositivos de control como roles de género, etarios, étnicos y raciales.

Venimos levantando la idea de que el epicentro de los derechos culturales es la posibilidad de participar de la producción y habitación de un mundo propio. La palabra propio, utilizada justamente en la medida de esta participación, lejos de todo enfoque purista en torno a 
matrices culturales o identitarias, junto a todo tipo de intercambios, colaboraciones. Lo que vemos como indispensable es la implicación real en la producción del territorio vital que luego puede ser transitado. Entre estas producciones ocupa un lugar privilegiado la propia producción de territorios, performances, ritualidades, que sostienen la voz y los enunciados colectivos, así como la capacidad de procesamiento y creación, frente a la masa de objetossentidos fabricados para el consumo cultural pasivo.

De igual manera podemos referimos al despliegue de esta plasticidad en el espacio. La producción material de los contextos, por ejemplo en la arquitectura popular, generando soluciones distintas en torno la idea de la casa, modelando la realidad en diversos tipos de formas comunales. Churuatas, palafitos, comunidades urbanas autocostruidas ${ }^{3}$, todos establecen relaciones muy concretas y diversas con los contextos, y por otra generan dinámicas muy diferentes en su interior y en la comunidad. La dimensión estética, de modelaje o construcción de esos espacios, así como la experiencia sensible de habitarlos, transitarlos, y estar en permanente recreación, muestra el ciclo transformativo de las materias más allá del sujeto y de la obra; en este caso en una de las obras más complejas de la actualidad, la urbe contemporánea.

Si bien podríamos seguir identificando ejemplos de actividades que evidencian la cualidad plástica y sensible de la materia, del cuerpo y de las subjetividades, lo importante aquí no es la enumeración de los campos, sino la singularidad de las producciones en cada caso, la cualidad de irrepetible de cada modulación de la vida, expresando su contexto y sus desdoblamientos. Lo irrepetible de las formas que, logradas en la materia por su fuerza de impresión, estarían en el centro de la experiencia estética que venimos describiendo.

\section{La experiencia estética de vuelta en la cotidianidad}

La experiencia estética no ha dejado de estar en la cotidianidad popular, solo que a partir del impasse colonial (Pérez-Wilke, 2016) y de la configuración de la modernidad se abre una brecha entre espacios y formas cualificadas como legítimas o no, en la cual la pujante producción popular quedó en la exterioridad del mundo moderno-colonial (Dussel, 1984). El nombre y la categoría de obra de arte, objeto de la estética, quedó reducido a espacios y actores de una clase de servicio a las élites, para la celebración, adorno y entretenimiento de tales. Inclusive si acompañadas de textos filosóficos referidos a lo sublime, al genio y al camino de la verdad, o administrando políticamente ciertos contenidos críticos, la obra estaba estaba referida a una experiencia acotada a un cierto sector social (Albán, 2013). Aunque en muchos casos los artistas modernos hacían una doble vida, produciendo materiales y experiencias al margen del oficio visible, estas obras que serían reconocidas como tales mucho tiempo después. Hoy día, las teorías y formas del arte contemporáneo, mantienen esquemas en los que, con algunas perspectivas de criticidad un tanto tautológicas y autorreferenciales, en muchos casos se

\footnotetext{
${ }^{3}$ Churuata: construcción indígena de vivienda colectiva de forma circular, hecha con madera y fibras vegetales. Palafito: construcción indígena de pueblos de rio elevadas sobre el agua. Comunidad urbana autoconstruida: comunidades de la periferia urbana, construidas por los propios habitantes, sin referencia a la planificación urbana.
} 
cuestionan solo de manera retórica estos temas, pues la clase artística, aunque sea marginal en el campo de saber, no deja de gozar de ciertos privilegios.

En la perspectiva que planteamos, se propone volver a la idea de la experiencia estética como un hecho procesual, parte de la vida social y del cual participa cualquier persona necesariamente, porque forma parte de la condición creadora vital del ser humano (Pérez-Wilke, 2017). La participación y vivencia de procesos de creación en los más diversos campos y lenguajes, con, para y desde todo aquel, se revela como un elemento existencial de vida o muerte. Planteada lejos de la vida y restricta a un sistema de clases, parece un asunto suntuario, electivo, fundando a menudo su valor en la inutilidad y gratuidad y destinada a unos pocos. Por el contrario nos reencontramos en su vinculación con el movimiento de la vida material y simbólica, asociada a las dimensiones afectivas, epistémicas, pedagógicas, eróticas, económicas que están en el centro de procesos vitales personales y comunitarios. El reconocimiento y recuperación de la experiencia sensible y su plena potencia en el campo de la vida cotidiana es un vector de trabajo indispensable.

Augusto Boal ${ }^{4}$ dijo en más de una oportunidad "Todos podemos hacer teatro, inclusive los buenos actores pueden hacer teatro" ${ }^{5}$ señalando el hecho de que los contextos y la formación profesional en los ámbitos cualificados del arte, tal como está concebida, puede dificultar la experiencia de vulnerabilidad y la verdadera creación escénica. La profesionalización obstaculiza la experiencia estética en lugar de promoverla, sin embargo también en ese caso permanece como derecho al alcance de todos(as). Esto no es solo una declaración; en su amplio trabajo en torno al Teatro del Oprimido, Boal desarrolla dispositivos estéticos para la atención concreta y colectiva de situaciones cotidianas de opresión. Los dispositivos desarrollados pretenden aportar soluciones, y generar debates para intervenciones efectivas en lo real, a partir siempre de experiencias de vida. Lo cual muestra por una parte los beneficios del trabajo en contextos no profesionales, y por otro la potencia de los recursos artísticos para atender problemas específicos.

La observación de estos dispositivos puede ser mucho más sutil, revelándose en signos y enunciados, movimientos corporales, cambios sonoros, solo perceptibles a la atención aguzada, en procesos de desaceleración y no por ello menos efectivos y/o registrables. La experiencia agenciada con el grupo de Mujeres de Alto das Pombas, en la ciudad de Salvador (Pérez-Wilke, 2017), a través de un espacio de juego, de autocuidado e intercambio centrado en la narrativa de relatos de vida de la mujeres, se reveló como dispositivo para provocar procesos creadores en torno a las categorías de memoria, imaginario y sensibilidad. En este caso, el espacio regular, abierto, democrático, de libre participación, sin expectativas espectaculares, permitió la aparición de una teatralidad cotidiana a través de la cual, mirar, presentar y también recomponer, recrear, las historias de vida individuales y el relato de la configuración de la comunidad. Se trataba de observar la emergencia de una poética de la

\footnotetext{
${ }^{4}$ Augusto Boal, (1931-2009) Actor y director teatral brasileño, creador del teatro del Oprimido. Técnica teatral y pedagógica de transformación social.

${ }^{5}$ Referido por Olivar Bendelak, Miembro del Centro del Teatro de Oprimido de Rio de Janeiro, en taller de Teatro Forum en la Ciudad de Salvador de Bahía, Brasil, 2008.
} 
cotidianidad al poner en común sus propias narrativas, en la voz y actuación de las mujeres que obraba un recrearse para sí.

Se hace imperiosa una democratización radical del acceso a la prácticas creadoras como condición humana y su reintegración plena a la vida cotidiana y prácticas extracotidianas colectivas. Vemos que la experiencia estética es un modo de interferencia o manipulación de las dimensiones rituales-simbólicas, que permiten fortalecer esos otros lugares de comprensión, de operación y de enunciación, reafirmándose como populares, más allá de los espacios, las formas legitimadas de arte (museos, teatros, salas de cine). Implica la asunción y el fortalecimiento del hacer porpular, incluso desde la condición de exterioridad al mundo legitimado, como vectores potentes de producción sociocultural, como expresión y realización de la propia vida comunitaria, que fabrica los mundos-contextos-realidades realmente existentes de pueblos invisibilizados.

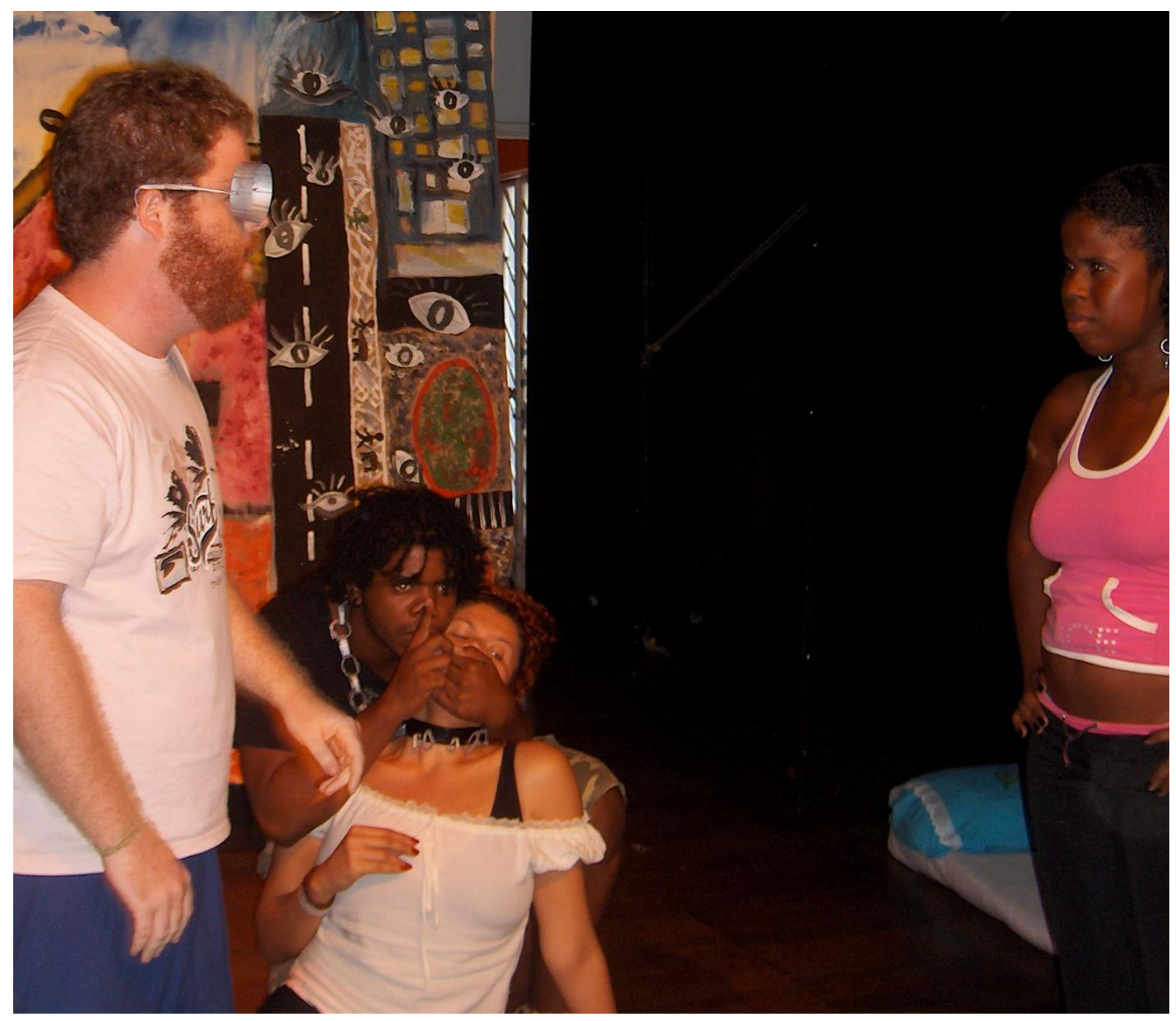

Figura 3. Taller montaje de Teatro del oprimido - Salvador de Bahia Brasil-2008. Fotografía Isadora Yanes. 


\section{Arte como tecnología de transformación de lo real}

La noción de tecnología, en este momento tan asociada a las máquinas y los sistemas informáticos, invoca aquí su sentido etimológico para cualificar las actividades de transformación de la materia (Dussel, 1984). Sentido este que permite comprender los dispositivos de creación estética, en tanto que artefactos que trabajan con la materia afectable, como formas de tecnología que operan en la configuración de la realidad. Nos referimos a una estética ocupada en transformación como poiesis, en la fabricación del mundo a través del trabajo con su condición de plasticidad. En ese sentido todas las técnicas de manipulación del sonido, del espacio, de color, del cuerpo, de la materia, de la construcción narrativa, visual, táctil, son acciones que marcan, modelan, afectan el mundo material y simbólico, y califican como tecnologías artísticas. Estamos de plano colocando el hacer artístico en el campo empírico fabril, pero no de las máquinas, si no de la experiencia vital, con los materiales tangibles e intangibles más sensibles de la vida, el cuerpo, la subjetividad, el imaginario, el espacio habitado, e inmersos en la cotidianidad de cada uno/a.

La racionalidad moderna con sus ideas de cientificidad y laicidad, generó, en relación a los saberes y prácticas de los pueblos periféricos, la interdicción y deslegitimazión de artefactos que operaban en la vida cotidiana, de significación cultural; trastocando la continuidad material-simbólica que activaban estos dispositivos. El desplazamiento que proponemos, en torno a la experiencia estética popular comprendida como techné artística, nos permite pensarlas, no ya como fórmulas estilísticas, si no como técnicas de interferencia de y en la realidad, como recursos de las manifestaciones sensibles en sus procesos de afectación y producción de territorio común. Esto implica reconocerles su plena legitimidad y efectividad como saber, su necesidad contextual y la plena evidencia del mundo que, a partir de ellas es producido.

Más allá de la materialidad de las artes plásicas o arquitectónicas, podemos ver el caso de la literatura. Pensemos en las analogías; si en lugar de concebirlas como figuras literarias, las utilizamos como dispositivos activos: ¿Qué hacen? Las analogías, entendidas como relaciones proporcionales entre dos términos que se ubican distantes pero en un cierto paralelismo, han sido leídas en la matemáticas, la lingüística o la filosofía. Traeremos aquí la perspectiva literaria de José Lezama Lima, cuyas figuras analógicas él mismo incorpora en su metafísica "Al aumentar el hombre su longitud de onda, sabe que su potencia se manifiesta en lo que he llamado la vivencia oblicua, que viene a decirnos que la imagen no se extingue, que nace en lo cercano e inmediato y renace en el eros de la lejanía" (Lezama, 2000, p. 287). Se trataría entonces, no de la distancia entre el sentido y la interpretación, si no de operaciones que se dan en un campo, en relación dialógica con otro distante sobre el que opera. En los textos de Lezama, esta fórmula aparece como eventos que se dan en un contexto, y se expresan de forma misteriosa y amplificada en otro; en ese sentido ejercen sobre él influencia, introduciendo elementos y condiciones desde el primer campo. Tal como las acciones rituales, que operan en el canto o la danza, para movilizar fuerzas que se expresan en la salud, el tiempo o la fertilidad. Formas de accionar en un campo desde otro campo (Figura 4).

Otro ejemplo aparece en manifestaciones africanas y afrodescendientes como las fiestas de San Juan en Venezuela, el Candomblé brasileño y Ubuntu sudafricano. En esas tradiciones, según 
sus propios oficiantes ${ }^{6}$, la música ocupa un lugar fundamental, estableciendo o propiciando, a través de las vibraciones producidas por el sonido, la conexión entre los planos físicos y espirituales. Lo cual podría explicar la resiliencia y persistencia de las manifestaciones afrodescendientes en toda América, y sobre la cual se han anclado numerosas luchas étnicas, antirracistas e identitarias en general. En el propio seno de los movimientos y militancias afrodescendientes hay un justo debate en torno a la folklorización a la que eran sometidas las manifestaciones afro, simplificándolas a su dimensión lúdica y exótica. Pensamos hoy que es necesario reivindicar las manifestaciones sonoras afro, como saber y tecnología, mas allá de las limitaciones del imaginario blanco, que ha construido en relación a estas prácticas.

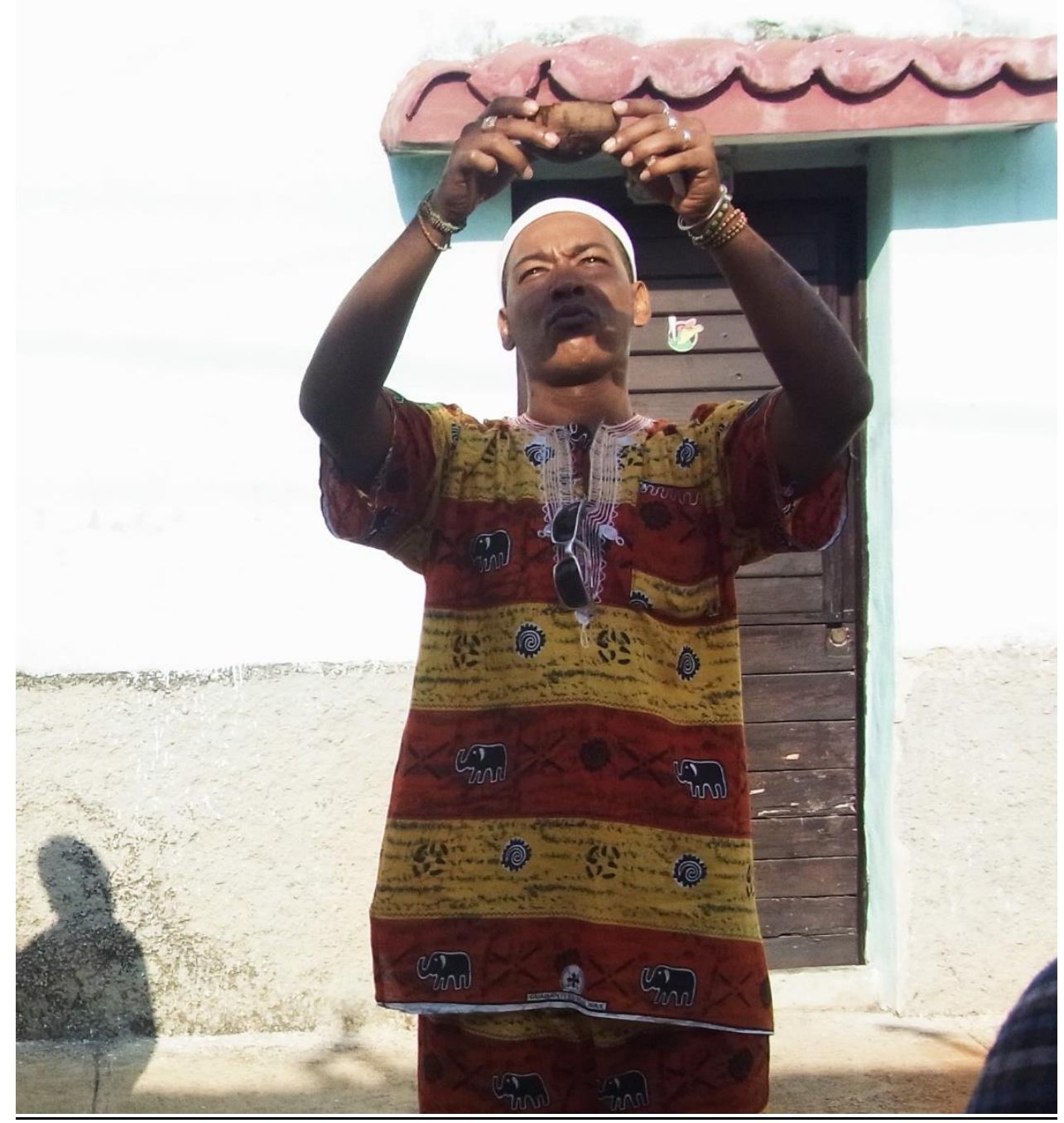

Figura 4. Nangareo Ritual - Matanzas, Cuba 2014. Fotografía Francisco Pérez

\footnotetext{
${ }^{6}$ Declaración del bailarín afrobrasileño Augusto Omolu en el Taller de Danzas del Candomblé, 2002, en el marco del Festival de Teatro de Occidente, Venezuela, 2003; y ponencia de Sibusiso Nkundlane, militante sudafricano sobre la sabiduría Ubuntu en el 1er Encuentro Internacional Diálogo de Saberes en torno a la Afrodescendencia, Maracay, 2014.
} 
De nuevo en el campo de la música, la medicina tradicional china también muestra experiencias curativas a través del sonido, en las cuales el mismo amplifica o sustituye el efecto de tratamientos de acupuntura. Es decir, que las vibraciones sonoras modifican los flujos energéticos que circulan por los meridianos corporales. Esto puede darse tanto escuchando el sonido grabado, con diapasones percutidos en vivo, o por el propio canto de los sonidos indicados. El hecho de que se produzca una disciplina, aún marginal como la musicoterapia, por una parte demuestra los fundamentos reales de estas prácticas antiguas, al tiempo que corre el peligro de contribuir a su invisibilización puesto que se configura como nuevo gueto de saber desvinculado de estas prácticas populares. Lo importante aquí es insistir en la cualidad operativa de los haceres vinculados a las formas que conocemos como artísticas, y que operan la agencia sensible, con efectos demostrados en prácticas populares.

Por último citaremos el dibujo, como forma de pensamiento y materialización directa de contenidos simbólicos emergentes. La imagen gráfica sobre las piedras, es de hecho una de los primeros elementos en el reconocimiento y estudio del hombre y la mujer en la antigüedad, y su fuerza se mantiene intacta como elemento de registro, expresión y creación humana. Muchas de las más complejas invensiones del ser humano han pasado por esa tecnología de creación que se asienta en trazos significantes, el diseño y la construcción de un mundo que nos habla desde cualquier soporte: un trozo de papel, de tela o un muro. Es evidente que la creación artística y sensible, ha estado generando elementos claves en la configuración del mundo que conocemos, y restituir este lugar operativo, garantiza que el tipo de racionalidad y tecnología con la que actúa sean reconocidas plenamente.

\section{Cuerpo común y experiencia de multiplicidad}

Habiendo desarrollado ya una crítica al sujeto reificado occidental, y postulado un pasaje del sujeto a la agencia colectiva (Pérez-Wilke, 2016), pasamos a identificar los aspectos puntuales de estas ideas en relación con la noción de experiencia estética popular en un contexto descolonial o transmoderno. En realidad, toda vez que hemos ubicado el cerne de la experiencia estética en la afectación, es decir en la interferencia, atravesamiento, impresión de unos agentes sensibles en otros, es evidente que los límites entre agentes se hacen difusos. Reaparecen aquellas ideas que expresa Peñalver (2000) en su lectura comparada de Levinas y Derrida, de las relaciones alteritarias en y por contaminación; destacando aquí una lectura antropofágica y no purista de esa contaminación. Esa transformación por lo otro, la otra y los otros, evidencia la presencia actuante unos(as) en otros(as) y en ese sentido, la crítica a la idea del sujeto se refiere menos a cuestionar unos límites definidos y a problemas identitarios de este o aquel sujeto, que a la habitual concentración de fuerzas autoritarias y unidireccionales de unos sujetos para actuar privilegiadamente sobre las y los otros.. Más que un asunto de identidad o un problema ontológico, un asunto de poder, de la posibilidad o no de participación creadora en la producción de mundo que identificamos como condición de los derechos culturales, es un asunto político, con incidencia en la circulación del ejercicio afectivo colectivo. 
Nos referimos aquí específicamente a la idea de comunidad y a la relación no antropocentrada de la agencia, que permite la comunión con otras formas de vida. Las ideas de masa abigarrada (Zabaleta, 2009), de multitud (Negri, 2003), de multiplicidades (Viveiros, 2010), de horizonte comunitario (Guitierrez, 2016) dan cuenta de una búsqueda concreta de comprender esas formaciones vitales colectivas. Si entendemos la comunidad como agente, veremos que estos dispositivos de mediación estética son formas de pensamiento y acción común (Figura 5).

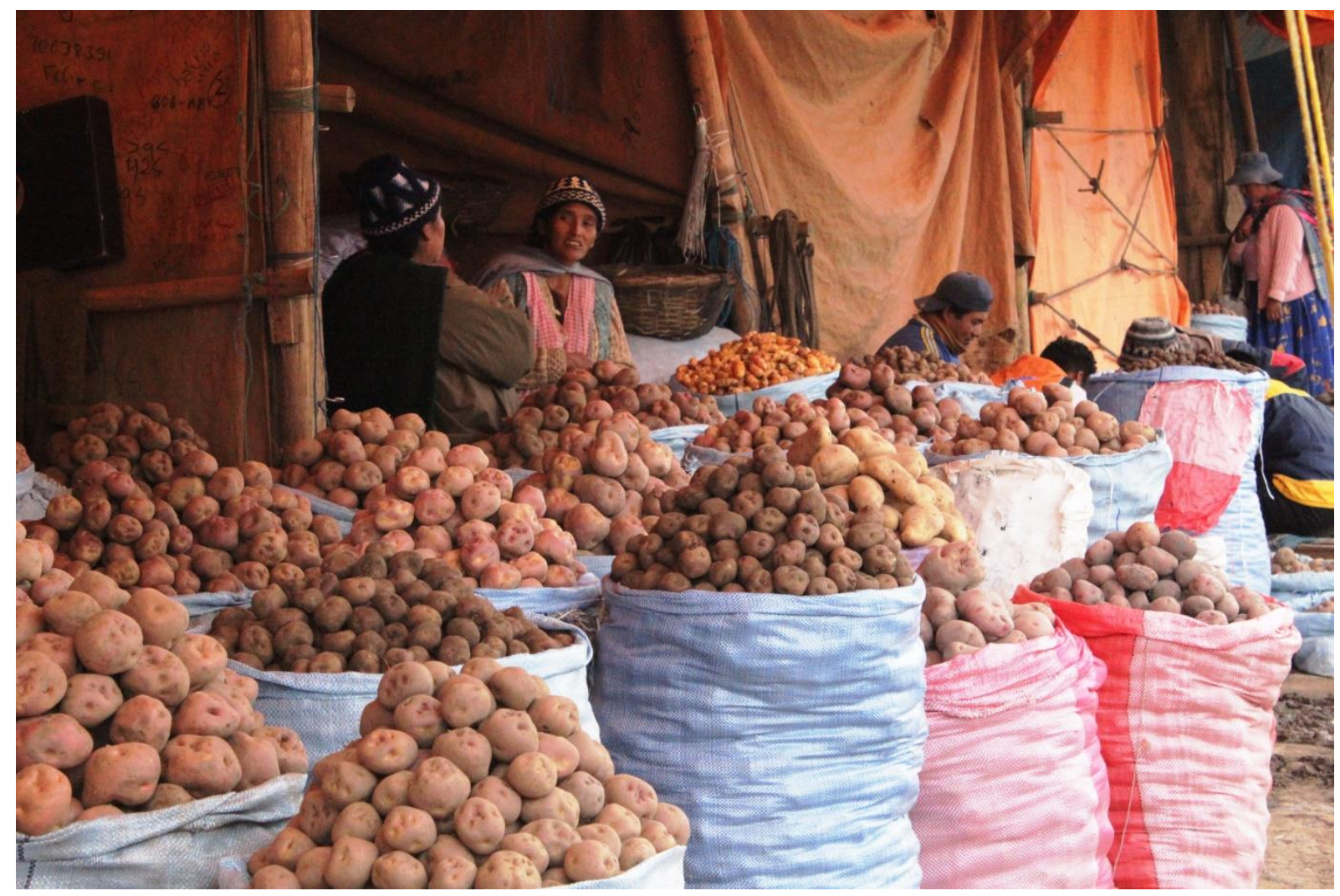

Figura 5. Mercado de El Alto, Bolivia 2013. Fotografía Inés Pérez-Wilke.

La expresión más empírica y material de ser comunitario vivido a través de la experiencia sensible lo encontramos en la comida común. Acción ritual de muchas comunidades, que nos exige evadir la narrativa de la comunión cristiana. Hay en otras tradiciones el cuerpo común, por todos producido (literalmente, a través de la siembra o de la elaboración del alimento) que en la ingesta es incorporado por cada uno(a), produciendo un cuerpo común. En este sentido aporta el saber, en el cuerpo, de ser más que un individuo, de lazos y continuidades materiales en la comunidad que sin duda excede a la persona, que al mismo tiempo la contempla y la contiene, en este sentido enriquecida, pues la agencia personal, está alimentada y protegida por la comunitaria.

Estas actuaciones plurales y heterogéneas, en el caso de las manifestaciones estéticas, tiene formas visibles en procesiones y danzas populares, cuyo cuerpo extenso toma forma y se muestra en ocasiones rituales. Como tecnología de corporeización masiva, vemos el candombe uruguayo, y así mismo el San Juan caribeño, el bloco de carnaval bahiano, los chibangeles en el occidente de Venezuela, donde la tradición afrodescendiente ha desarrollado ese cuerpo danzante masivo. Son dispositivos de movilización mítico-política de sujetos colectivos subalternos del mundo afroalatinoamericano, asentados en sólidos acervos con tecnologías para la cohesión, sincronicidad, resonancias de colectividades fundados en códigos comunes 
abiertos a la improvisación y creación, muchas veces sin un liderazgo muy claro, que se va moviendo de lugar. Nos interesa señalar aquí como se arriba a esta corporalización colectiva a partir de determinados saberes, en un lenguaje de pasos y ritmos que amasados por generaciones, continúan repitiéndose y transformándose en el tiempo y en el espacio. El cuerpo y la persona entran, de este modo, en diálogo con otras escalas de la ciudad, con otros danzantes en el tiempo y con otros planos de lo real. Recordando el estudio de Graziela Rodrigues (1997) en torno a los reizados de Minas Gerais, circulando en procesión por el pueblo, se atraviesan también umbrales y pasajes de otros planos y tiempos.

En otro campo expresivo, el reconocimiento de los flujos creadores de la tradición oral, ampliamente utilizados en los contextos populares como estrategias de continuidad, apropiación, difusión actualización en mitos, canciones, declamaciones, oraciones, rezos, cuentos, anécdotas, y reeditado en formas actuales de hip hop y otras líricas escénicas, muestra otras formas de subjetividad colectiva que vienen produciéndose y modificándose a lo largo de grandes períodos de tiempo. La historia que viene siendo transmitida, encuentra en cada nueva narración, en cada nueva voz, un nuevo cuerpo, que recoge y recrea una voz múltiple; la voz colectiva habla en cada uno(a) y a la vez se transforma, voces de lugares y tiempos distintos en un solo cuerpo, y a la vez muestra el camino de la misma idea operada por muchas voces en tiempos distintos.

Esta experiencia de agencia colectiva y de multiplicidad permite así pensar la inversión de perspectivas, de los tránsitos de doble vía, el afectante es afectado, el agente es agenciado. El cuerpo de tejidos colectivos, intenso, múltiple, plástico, vulnerable al que nos referimos, y que de muchas formas se intenta controlar, dormir, domesticar, (Rolnik, 2007) se rebela y se sostiene creador como condición para la vivencia plena en el cultivo de la vida.

\section{Contra-interferencia}

Si se piensa la actividad artística, tal como venimos colocando, operando en la germinación de la subjetividad, y mediando los campos eróticos, pedagógicos, políticos y económicos, reconocemos dispositivos estéticos que disputan la potencia productiva de la realidad a favor de las agencias populares. En una conferencia en la ciudad de Caracas, Ramón Grosfoguel (2017) decía que el arte descolonial debe generar mecanismos para interrumpir el control del capital sobre las subjetividades subalternas. Se refería a una acción subterránea, en el fundamento de las culturas y de la civilización actual, como dispositivos operando sobre la sensibilidad más íntima de cada uno, que expresa los supuestos civilizatorios.

En este sentido la acción artística popular en diversos contextos urbanos, especialmente en los más áridos, consiste en producir corrientes críticas desde el discurso sensible. Estos discursos, que muchas veces se realizan (a falta de cuerpos y acervos tradicionales o por elección e identificación con código globales) a partir de los contenidos producidos para el consumo por la industria cultural, pueden lograr, sin embargo, la producción de territorios propios. Es decir, que aparece la necesidad y la posibilidad de creación popular, por apropiación y uso creador a partir de elementos del propio detritus urbano contemporáneo, sin que esto implique una pérdida o renuncia a la capacidad productiva. 
Es evidente que esto no siempre se logra con éxito, Mario Rodríguez ${ }^{7}$ se refiere a sobreconsumo, como el límite de esta capacidad de incorporación propicia a continuidades y potencias culturales. La disputa que habita en el inconsciente colonial (Rolnik, 2011), muestra poderosos agentes, con los que se está en pugna y que pueden colapsar la capacidad de apropiación creadora y disruptiva del material circulante para el consumo. Es importante entonces mantener una perspectiva crítica y una actitud participativa constante que sostenga la presencia de la comunidad y sus integrantes en lo producido. Se trata de una vía de creación popular emancipadora que da la vuelta a la interferencia de las formas de control social de la subjetividad, en las actividades de producción y creación común, generando lo que estamos llamando contra-interferencias. Esto implica que a partir de las condiciones y materiales coloniales, en contextos donde los insumos locales han sido devastados o fragmentados hasta un punto que es difícil apoyarse en ellos para iniciativas de producción local, se logren formas de apropiación creadora que les permiten una producción propia con cierta autonomía discursiva y con plena potencia de territorialización. Ya José Luis Omaña (2017), ha desgranado algunos ejemplos en este sentido. Refiriéndose a movimientos culturales donde vemos cómo se generan, a partir de contenidos puestos en circulación por la industria cultural, a través de un ejercicio de incorporación crítica, la modificación de los marcos de interpretación o de uso, la mixtura entre materiales de diverso origen, creaciones, acciones, propuestas locales potentes para quebrar la interferencia de los mecanismos de biocontrol social, a la vida productiva. Esto implica una especie de cimarronaje sensible ${ }^{8}$, es decir, el desarrollo de tácticas de fuga a la domesticación, y la capacidad de producir, defender y cuidar de nuevos territorios habitables para la experiencia vital sensible.

Un ejemplo actual podemos verlo en las formas que toma el movimiento hip hop en las ciudades latinoamericanas. La apropiación por parte de las comunidades urbanas periféricas, en varias ciudades latinoamericanas, especialmente aquellas étnicamente diferenciadas, en primer lugar las afrodescendientes, pero también comunidades con fuerte marca indígena generando formas sui generis de rap y hip hop. En el caso boliviano vemos el trabajo de Nina Uma (Perez-Wilke, 2016), mujer, rapera, y de ascendencia indígena, se apoya en la interferencia hip hop, para generar una narrativa contra el poder masculino, colonial, presente en la propia práctica del rap, generando una textura musical y discursiva distinta de los sonidos importados que fueron asimilados.

Vemos también el caso de la configuración territorial de clases en la ciudad de Caracas, que instauró una vinculación del este de la ciudad con las clases pudientes y del oeste de la ciudad con las clases medias bajas y pobres. Esto no es cierto en rigor, pues justamente en el este de la ciudad se encuentra una de las más grandes comunidades autoconstruidas del continente, el conocido barrio de Petare. Sin embargo, las clases altas se atribuyen el dominio del este, que en realidad ha devenido sureste. Frente a esto, en una investigación del Ejército comunicacional de Liberación', publicada en el libro Mural y luces (2011), sobre la pintura urbana de la ciudad, emerge la categoría de Oestética (Figura 6), para referirse a las formas y

\footnotetext{
${ }^{7}$ Entrevista a Mario Rodriguez realizada en La Paz, Octubre 2013. En Pérez-Wilke Inés, 2016 Op.cit.

${ }^{8}$ Por cimarronaje se conocieron a los esclavizados que huían de las haciendas, logrando en muchos casos constituir comunidades libres.

${ }^{9}$ Organización social radicada en Caracas, Venezuela; dedicada a la comunicación popular.
} 
necesidades expresivas populares, asociadas a cierto tipo de combate de imágenes y cimarronaje cultural. El movimiento se apropia no solo de elementos de la corriente hip hop, tanto en la expresión grafitera, como en el rap, para contar otros historias y otros sentires y construir espacios de reconocimiento, sino que hace un giro sobre la categoría estética para garantizar lugares y formas de habla, que los registren.

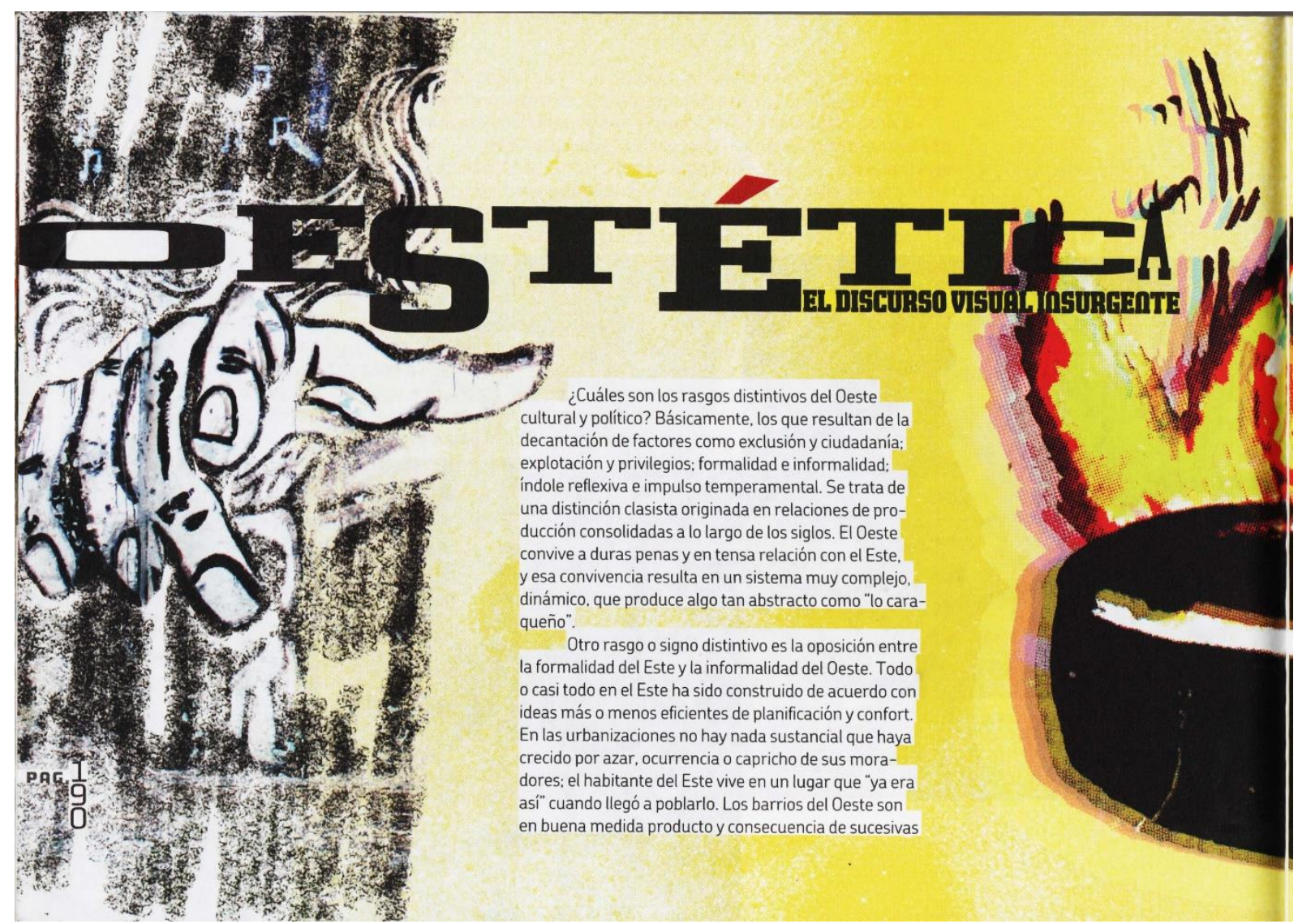

Figura 6. Oestética. Ilustración del libro Mural y Luces, 2011. Ejeército de Guerrilla Comunicacional.

Fuente: captura de pantalla de https://issuu.com/ejercito.comunicacional/docs/mylfinalwev

Pensamos también en el movimiento a menudo contradictorio que se da en determinadas formas de música, comercializada como latino-caribeña (Changa, pagode, reggaeton, trap, dance hall) que basa su mercadeabilidad en referencias al cuerpo de la mujer. El tratamiento que se le da a la mujer en las imágenes audiovisuales promocionales la muestran casi sin rostro, toda la atención en fragmentos del cuerpo en que parecen fortalecer patrones patriarcales y de cosificación. Sin embargo, algunas mujeres han usado este espacio de exposición y de colocación del tema sexual como vector de liberación del cuerpo, para afirmar su libertad de movimiento y expresión, no culpabilizada y desvinculándolo del objeto al servicio masculino. Esto implica para la mujer asumir el erotismo y la expresividad plena del cuerpo femenino, hecho tabú y asociado a prostitución, pornografía, etc., como derecho, por y para sí, por voluntad y goce propio. En el baile urbano popular, tanto tradicional afrodescendiente, como recreaciones contemporáneas, encuentra un lugar de contestación a partir del propio lugar de cosificación, en el que la plena expresividad de un erotismo inmanente, no se asume ni pecaminoso, ni deudor para con el varón. 
La perspectiva popular desde la cual se vivencia el mundo encarna entonces un lugar privilegiado de comprensión, con saberes y formas propia, así como capacidad de procesar las fuerzas de interferencia a su práctica creadora y productiva, reutilizándolas de modo insurgente.

\section{Conclusiones}

Una vez identificado el lugar de la sensibilidad humana y sus cualidades operativas de plasticidad, contacto, desaceleración, porosidad, autopoiesis, como formas habilitadas de producción realidad social, se evidencia la necesidad de restituir la potencia de la experiencia sensible y creadora a la vida comunitaria, cotidiana e insurgente para la salud y vitalidad de los pueblos. Dejamos registro de casos que, como vertientes metodológicas fundamentan un registro, a menudo obviado, de experiencias que vienen realizando colectivos, movimientos sociales, agrupaciones artísticas y culturales de base, que se ofrecen, como referentes para la experimentación sensible, para la producción sociocultural comunitaria y para una reflexión académica en diálogo diversos contextos. Encontramos aquí elementos concretos para un abordaje del campo de la estética, del estudio de la producción material y simbólica de subjetividades, a partir de elementos vitales de las realidades populares con capacidad de incidencia a largo plazo en las dinámicas imaginarias, simbólicas y materiales de la contemporaneidad.

Las consecuencias geopolíticas, económicas y culturales pueden entreverse: Puesto que las fuerzas y las marcas inscritas en la materia afectable, generan corrientes análogas, relatos y correlatos, resonancias, secuelas, que se materializan en el territorio, es la configuración de lo real. Cada experiencia alimentada es una fuerza social y política, que puede ganar agencia y control sobre la circulación material y simbólica, es decir, puede ganar poder. Las tramas de afectaciones, analogías e intercambios que constituyen campos en la economía de la producción sensible y luego simbólica, ocupan un lugar central en las dinámicas culturales del mundo actual, y lo que se aspira es hacer visibles las formas de operarla desde el campo popular y en favor de la vitalidad de los pueblos

\section{REFERENCIAS BIBLIOGRAFICAS}

Albán A. (2013). Pedagogias de a Re-existencia. Artistas indígenas y afrocolombianos. En Walsh, C. (Ed) Pedagogias decoloniales: prácticas insurgentes de resistir, (re) existir y (re) viver. Quito, Ecuador: Ediciones Abya Yala.

Bautista, J. (2014). ¿Qué significa pensar desde América latina? Marid: Akal.

Bautista, J. ((2016). Juan José Bautista Con Caracara [Fuente] Youtube. Recuperado de https://www.youtube.com/watch?v=cVhO_Kg2Xc4

Boal, A. (2005) Teatro do Oprimido. Rio de Janeiro, Brasil: Civilização Brasileira.

Dussel, E. (1984). Filosofía de la producción. Bogotá, Colombia: Nueva América. 
Ejército comunicacional de Liberación. (2011) Mural y Luces. Caracas, Venezuela: Ejército Comunicacional de Liberación.

Grosfoguel, R. (2007). Entrevista a Ramon Grosfoguel. Revista Polis, recuperado de: https://journals.openedition.org/polis/4040

Kant, E. (2001). Crítica del juicio. Madrid: Espasa Editorial.

Lezama, J. (2000). La posibilidad Infinita. Madrid: Editorial Verbum.

Mignolo, W y Gomez, J. (2012). Estéticas descoloniales. Bogotá, Colombia: Universidad Distrital Francisco José de Caldas.

Negri, A. (2003). Del retorno: Abecedario biopolítico. Madrid: Debate.

Omaña, J. (2017). Grupo Caracara: Asentar Ideas. [Fuente] Youtube. Recuperado de: https://www.youtube.com/watch?v=_JEQNInDEo4

Peñalver P. (2000). Argumentos de Alteridad. La hipérbole metafísica en Enmanuel Lévinas. Madrid: Caparrós Editores.

Pérez-Wilke, I. (2016). La Experiencia de l@s otr@s. Claves para una Heterología Suramericana. (Tesis doctoral). Universidad Bolivariana de Venezuela, Recuperado de: https://bit.ly/2CAbAeG

Pérez-Wilke, I. (2017). Otras narrativas, la mujer pueblo y sus relatos de vida. Caracas, Venezuela: Editorial UBV.

Rodrigues, G. (1997). Bailarino, pesquisador, interprete. Processo de formaçao. Rio de Janeiro, Brasil: Funarte.

Rodriguez, M. (2004). Para seguir viviendo. Reconfiguraciones en las relaciones entre juventud, sociedad y educación. El Alto: Ediciones Wayna Tambo.

Rolnik, S. (2007). Cartografia Sentimental: Transformaçoes Contemporáneas do desejo. Porto Alegre: Sulina-UFRGS Editora.

Rolnik, S. (Productor). (2018). Sugerencias para resistir al abuso de la potencia de creación [Audio Podcast]. Recuperado de: https://bit.ly/2SQ4AV2

Schopenhauer, A. (2003). El mundo como voluntad y representación. Madrid: Trotta.

Viveiros, E. (2010). Metafísicas Caníbales. Buenos Aires, Argentina: Katz.

Zavaleta, R. (2009). La autodeterminación de las masas. Bogotá, Colombia: CLACSO. Siglo del hombre. 